\title{
The development strategy of Rizhao agriculture Tourist Park Yuan Xiaoli ${ }^{1, a}$ \\ ${ }^{1}$ Rizhao Polytechnic, Rizhao, Shandong, China \\ a184379442@qq.com \\ * Yuan Xiaoli
}

Keywords: Agricultural tourist park; Development; Strategy

\begin{abstract}
Agriculture always play the predominant role in the industrial structure of Rizhao city, so it is of great significance to develop leisure agriculture. In order to make agricultural tourist park develop in a healthy and order way, the first problem need to be solved is that what kind of services can it provide, and state clear its market positioning. It not only beautify the tourist park by professional landscape design, but also apply advanced high technology to plant good stock, which improves agricultural products quality and output, and finally promote economic and social benefits. In addition, it also enhance the cultural connotation so the park has diversified income sources with better cultural taste. The source of returns of successful tourist parks are characterized by diversity. Therefore, the park construction needs to take full account of natural resources and economic conditions, so as to develop steadily and obtain ecological, social and economic benefits in sustainable growth.
\end{abstract}

\author{
日照农业观光园的发展策略 \\ 袁晓利1, a \\ 1日照职业技术学院 日照 山东 中国 \\ a 184379442@qq.com \\ *袁晓利
}

关键词: 农业观光园;发展;策略

中文摘要 农业在日照市的产业结构中一直占据首要地位, 发展休闲农业具有重要的意义。 为使观光园的发展健康有序, 首先要解决的问题就是园区能给哪些顾客提供什么样的服务, 明确观光园的市场定位。然后通过专业的景观设计美化观光园区, 通过种植、养殖优良品种, 改善农产品品质，提高产量，以及应用高新技术，改变传统农业生产方式，提高经济效益和 社会效益。深挖文化内涵, 使得园区收益多元化, 提升观光园的文化品位。成功的观光园区, 其收益都具有多元性的特征。园区建设需要充分考虑自然资源和经济条件, 以期稳步发展, 获得持续增长的生态、社会、经济多方效益。

\section{1. 引言}

日照市, 位于山东省的东南部, 旅游业发展迅速, 伴随兴起的是日照市城郊农业观光园。 日照市特色农业较多, 特色种植业面积已突破 140 万亩, 为日照市乡村旅游的良性发展奠定了 坚实基础。截止2017年底, 各类农业观光园已达百余家, 这些农业观光园的功能各异, 但都 朝气蓬勃, 生命力旺盛。这些观光园还处在成长初期, 难免出现一些问题, 例如园区活动内 
容过于单调, 游客的体验不够丰富, 园区发展核心不够明确, 缺乏特色等。在这种背景下, 开展日照市农业观光园发展问题研究，以促进日照市农业观光园的健康有序发展。

\section{2. 日照市发展休闲农业的条件}

2017 年，日照市全年城市居民人均可支配收入 30790 元，比上年增长 $8.6 \%$ 。城市居民人均 消费支出 19176 元, 增长 $6.8 \%, 2017$ 年日照市人均地区生产总值 68848 元, 约 1 万余美元, 截至 2017 年底, 日照市城镇常住人口增加到 303.68 万, 城镇化率达到 $58.65 \%$ 。人均可支配收入的 增加和城镇化为休闲农业的发展创造了物质条件和市场机会。经济条件的改善和消费观念的 转变, 人们在观光旅游、休闲度假等方面的消费需求逐年加大。随着居民的生活水平不断提 高, 越来越多的人会有度假和休闲的需求。并且, 前往郊区休闲旅游的城市人口基数与城市 规模成正比。我国实施每周 5 天工作制, 全年共有 11 天法定节假日。特别是政府部门、企事业 单位实行强制休假制度，将更多的居民加入到休闲农业旅游的队伍。

\section{3. 农业观光园的定位}

目前，日照市的休闲农业旅游刚刚起步，有些园区急功近利，盲目跟风建设，缺乏明确 的定位。要想长期健康持续发展, 其中首先要解决的问题就是园区能给哪些顾客提供什么样 的服务。

首先, 农业观光园的定位要分析园区的地理位置, 周边区域经济发展水平, 以及观光园 自身的特色资源和投资规模，明确观光园的发展方向,避免盲目开发导致的生态环境破坏以及 可能的经济。其次, 环日照市区, 自然资源相似度高, 应着力塑造园区鲜明而独特的形象, 并且通过市场营销手段, 将其准确传递给顾客。比如, 寿光生态农业观光园, 以其现代化的 农业种植技术, 区别于其它观光园, 获得快速成长。再次, 分析观光园的优势和劣势, 确定 发展方向和应该回避的风险。依据自身资源, 发挥优势项目, 切忌不分侧重, 什么项目都开发。 最后要确定目标顾客。通过市场营销手段, 发现并培养忠实顾客, 关注消费者的需求和偏好, 做消费行为研究, 时时关注消费需求的变化。

\section{4. 专业的景观设计}

农业观光园景观同时具备园林景观和农业景观的特征，是二者的结合体。既要适合旅游 观光, 又要满足农业生产。其景观设计既不能完全照搬城市景观的设计方法, 也不能完全任 其自然, 不做任何修饰与改变, 景观设计显得尤其重要。首先, 农业观光园的景观设计既需 要为游客提供视觉上的享受, 又要能够带动游客的积极性, 主动参与体验园区的各种活动。 不仅需要考虑景观的静态表现, 更需要着重体现它的动态效果, 如游人在参与到农田耕作或 果园采摘的过程中形成的动态景观。其次, 创意景观要与园区的整体自然景观相协调统一。 再次, 农业观光园作为农田用地, 首先得具备生产功能, 同时它作为旅游休闲区, 供游客观 光休闲, 又得具有观赏功能。最后, 农业观光园区的景观同时具备高科技运用与艺术美学的 功能, 在进行农业观光园的景观设计时, 需将科学技术作为前提, 将其与艺术表达有机结合, 既能体现高科技教育功能, 又能使人们得到美的视觉享受。

\section{5. 积极应用高新技术}

现代农业的发展离不开新技术的应用, 而兼具展示功能的观光园更是离不开高新技术的 推广。要提高农业观光园的价值, 必须面向市场, 以农业为主, 积极应用现代化的农业科学 技术, 走综合发展的道路。作为综合体的现代农业观光园, 不仅集成了农业生产、旅游观光, 
实现了综合发展，而且跨界的融合使得市场前景广阔，具有无穷的发展潜力，具有不可估量 的社会效益、经济效益和生态效益。

\section{1 新品种、新技术的应用}

优良品种对作物品性的提高是革命性的，通过培养种植、养殖优良品种，改善农产品品 质, 是提高产量, 保障食品安全的生产基础。同时现代农业的发展离不开新技术的应用, 利 用新技术进行生产，使观光园拥有先进的技术水平和适宜的生产规模。

\section{2 生产方式的创新}

改变传统农业生产方式，降低化学肥料和生长调节剂等在农业生产过程中的使用，控制 因此造成的食品污染。积极推行有机化的生产模式, 更多产出有机农产品, 满足高端市场需 求。

日照蓝莓近几年来异军突起, 在蓝莓种植过程中, 创新的生产方式贯穿始终。蓝莓发展 初期土壤改造靠的是有机肥，管理中期不用化肥、农药，靠的是微量元素、天网、灭虫灯等 等。灌溉采用先进的滴灌技术，可节水 $60 \%$ 以上，并且半自动化的管理，减少了大量的人力 成本。并且蓝莓可以种植在山岭薄地, 不仅保持水土, 并且能避免与农作物争夺土地, 生态 化的种植模式, 直接减少农药化肥等对环境造成的危害。创新的生产方式不仅为当地带来可 观的经济效益，同时还减少了农业污染，带来了社会效益。

\section{6. 深入发掘农业文化遗产}

文化与自然是旅游业经久不衰的主题，农业观光园中蕴含丰富的民俗、历史、科技、精 神等文化内涵。这些富有趣意的文化知识, 体现在各种各样的观光游览项目中, 不仅能向游 客普及农耕文化知识, 还能增加旅游中的趣味性以及知识性, 同时使园区的文化品位得到提 升。农业观光园能使游客体验、感受当地特有的风俗和文化鬼米力, 这对于保护与传承地域农 耕文化具有重要意义。传统农业保留至今, 其中最吸引人的是农业文化遗产, 这是游客的兴 趣所在。农业文化遗产与现代农业技术的结合，是农业观光园的重要发展方向。

\section{7. 收益多元性和可持续发展}

\section{1收益多元性}

国内外成功的观光园区, 其收益都具有多元性的特征。农业观光园本身就是一个综合体, 不仅可以从园区的农业种植和动物养殖中获益, 并且可以从门票、餐饮、住宿、生产过程展 示、展览以及旅游接待、高端旅居养老等环节获益。

目前日照市的农业观光园收益主要集中在门票收入和农产品销售收入, 可以将养老基地、 康疗基地、有机农产品开发组合在一起，各要素之间相互支撑、相互带动,共同发展。

\section{2 可持续发展}

观光农业园应以保持生态系统的可持续性为基础，不能破坏自然，不宜进行大规模的人 工建设。现代农业技术的发展使我们可以在顺应自然生态发展规律的同时获得较大的收益, 在现代农业技术支持下发展的观光农业型园区更应以贴近自然为特色, 在规划建设中强调保 护和合理利用自然景观, 崇尚自然生态美学的审美观。观光农业型园区的人工建设应尽量减 少, 应充分利用原有农业资源。规划布局要因地制宜, 合理开发利用自然的山水地貌, 减少 基础性投资。人工建设应尽量体现因地制宜的原则。

农业观光园的建设应坚持适度开发原则。一方面不要超出环境承载能力。对农业观光园 的规模进行控制, 保证对园区内的农业环境、生态系统予以有效保护。对游客规模和活动方 式进行控制, 避免对园区环境的大规摸、深层次破坏。对人工建设的规摸、形式等进行控制, 尽量避免对环境产生难以恢复的破坏。另一方面, 开发的程度与当地的社会、经济条件相适 
应。采用当地生产力水平可承受的先进农业技术，不盲目追求高新技术而造成经济负担，阻 碍农民生活水平提高。

农业观光园的规划建设要兼顾近期和远期的利益, 以可持续发展理论和生态经济学原理 为指导，做出目标明确的分期发展舰划，从而避免盲目冒进，使园区稳步发展，获得持续增 长的生态、社会、经济多方效益。

\section{8. 结束语}

发展农业观光园，对于高新技术在农业的应用和推广，促进农民收入增加，推进社会主 义新农村建设, 满足城镇居民的休闲需求具有重要的意义。随着日照农业观光园的萌芽发展, 其影响力也在与日俱增。对于未来日照近郊农业观光园良性有序发展, 我们满怀信心。

\section{References}

[1] Li baoyin, 21st century ecological agriculture model agricultural sightseeing park, Journal of Henan Vocation-Technical Teachers College, 2002.

[2] Zeng mingzi, a brief discussion on landscape design of modern agricultural sightseeing park, Periodical Agency of Yangtze University, 2014.

[3] Wang bin, the formation and research of the concept of leisure and sightseeing agriculture science and technology park, Chinese Horticulture Abstract, 2010.

[4] 2014-2019 China agricultural sightseeing park market development analysis and investment prospect forecast report, www.cnscdc.com.

[5] Shen qingtao, on the comprehensive innovation concept of eco-agriculture sightseeing park model, Journal of Anhui Agricultural Science, 2007.

[6] Wang jianling, discussion on the combination mode of agricultural technology and tourism, Shandong Agricultural Science, 2011.

[7] Beijing yongxian design institute dragon lake bay project team, Special research on agricultural sightseeing park, 2013.

[8] National economic and social development statistical bulletin of Rizhao in 2017, 2018. 